\title{
An Exploration of Metacognition in Asynchronous Student-Led Discussions: A Qualitative Inquiry
}

\author{
Martha M. Snyder \\ Laurie P. Dringus \\ Graduate School of Computer and Information Sciences \\ Nova Southeastern University
}

\begin{abstract}
Research is limited on how metacognition is facilitated and manifested in socially situated online learning environments such as online discussion forums. We approached metacognition as the phenomenon of interest with a methodological objective to evaluate the relevance of a metacognition construct. We also had a content objective to study student-led facilitation of discussions as a strategy in promoting metacognition. The purpose of this study was to explore: (1) where metacognition is evident in studentled online discussions and (2) how students' experiences leading and participating in student-led online discussions relate to their awareness of learning. Content analysis was used to analyze discussion forum transcripts and interpretative phenomenological analysis (IPA) was used to analyze responses to an openended questionnaire. We concluded the metacognition construct was useful in helping us understand and organize the data and student-led online discussions can be an effective strategy for helping students develop dimensions of metacognition including knowledge, monitoring, and regulation. However, in order for students to use these skills effectively, instruction, motivation, and guidance are neededparticularly in relationship to the regulation of metacognition and co-construction of meaning.
\end{abstract}

\section{INTRODUCTION}

The study of metacognition gained popularity in the late seventies and early eighties as a promising area of inquiry to help develop methods of teaching children and adults to "comprehend and learn better in formal educational settings" (Flavell, 1979, p. 910). Metacognition is generally defined as how we monitor and control our own cognition (Flavell, 1979; Young \& Fry, 2008). Hart's (1965) seminal work about the feeling-of-knowing experience and its use to indicate what is stored in long-term memory, paved the way for further studies focused on metacognition. Flavell (1979) presented a conceptual model of cognitive monitoring and encouraged educational researchers to develop interventions to increase cognitive monitoring given his conviction that more cognitive monitoring would lead to better learningespecially for children. Garner (1990) advised of the need to consider context when using various strategies to enhance learning.

Metacognition within the context of an online learning community is the focus of our present study. Akyol and Garrison (2011) defined metacognition in an online learning community as "a set of higher knowledge and skills to monitor and regulate manifest cognitive processes of self and others" (p. 184). This definition implies metacognition is not necessarily developed individually but can be co-constructed 
within an online social context. For example, Akyol and Garrison explored metacognition as a central construct to describe an awareness of one's learning and the ability to control and construct meaning in an online community of inquiry (CoI) (situated in an online course). They suggested that "metacognition mediates between reflection and action” (p. 186), an important aspect of understanding the degrees to which students are able to be critical thinkers and inquirers.

Akyol and Garrison (2011) emphasized that sharing cognitive experiences is important to learning; metacognition is "seen to mediate between internal knowledge construction and collaborative learning activities" (p. 185). In this regard, there is an aspect of "community and sharing thinking” (p. 189) in knowledge acquisition that also suggests learning to be a shared process. In metacognition, there is a collaborative aspect or "co-construction" of three dimensions of cognition including knowledge, monitoring, and regulation. Co-construction is an aspect that is often applied to online learning environments and is consistent with social constructivism theory (McInerney, 2005; Palincsar, 1998) and with the Community of Inquiry (CoI) model in online learning (Garrison \& Arbaugh, 2007).

Researchers who have studied metacognition in traditional learning environments (Mayer, 1998; McCabe, 2011; Young \& Fry 2008) and in online learning environments (Akyol \& Garrison, 2011; Choi, Land, \& Turgeon, 2005) suggest that the more adept learners are at using metacognitive skills, the more academically successful they will be. In two studies that explored undergraduate students' metacognitive awareness in traditional learning environments, McCabe (2011) found that students' awareness of metacognitive skills was low to non-existent and metacognitive awareness may be improved through targeted educational interventions. Choi et al. (2005) studied the effectiveness of peer-questioning strategies to facilitate metacognition during online small group discussions. While the authors found the scaffolding of questions to be helpful in encouraging other students to ask questions, they did not find any differences in the quality of questions or learning outcomes. However, their study suggested that there is value in the implementation of instructional strategies to facilitate "learner's reflection and knowledge reconstruction in online small group discussion" (p. 506). Their results also emphasized the value of testing and revising instructional strategies aimed at facilitating metacognition. With an understanding of how to assess metacognition in online discussion forums coupled with the awareness of instructional strategies that are effective in developing metacognitive skills, improvements can be made to the design of online discussions that foster successful learning outcomes.

\section{THEORETICAL FRAMEWORK}

The metacognition construct is a fast-growing trend of discovery-in both theory and practice-in online learning, and interest in the construct extends the popular Community of Inquiry (CoI) model (Garrison \& Arbaugh, 2007). In a CoI, it is assumed learning takes place as a result of the interaction of three elements: cognitive presence, social presence, and teaching presence (Garrison, Anderson, \& Archer, 2000).

The CoI has been accepted as a useful framework for research and practice in online learning environments (Garrison \& Arbaugh, 2007) and was used as the theoretical framework for the initial development of Akyol and Garrison's (2011) metacognition construct as it applies to the learning process in a CoI. Akyol and Garrison situated their metacognition construct at the intersection of cognitive presence (representing the inquiry process) and teaching presence (representing the shared teaching roles and responsibilities of all participants in a community of inquiry). They suggested these two presences were "essential to better understand and assess metacognitive knowledge and skills of learning in an online community of inquiry” (p. 186).

This present study is based upon Akyol and Garrison's (2011) work, which revealed that individuals apply knowledge and skills to monitor and regulate cognition in themselves and others. Little, however, is actually known about this phenomenon in online discussions specifically. As a result, this study examines the metacognition construct and its dimensional scale (see Figure 1) for its theoretical and practical significance in online discussions. 
We employed student-led facilitation (Baran \& Correia, 2009) —also known as student-led discussionsas an instructional strategy to learn to what extent students are able to "co-construct" meaning when participating in discussions with peers. In student-led discussions, the instructor maintains a minimal facilitative role in managing the online discussions while students take turns leading the discussion. Therefore, we examined both the metacognition construct as it manifested in student-led online discussions, and we examined the effectiveness of student-led online discussions as an instructional strategy to promote metacognition.

Guided by pre-established dimensions and indicators of the metacognition construct proposed by Akyol and Garrison (2011), our study describes what we observed in the discussion forum transcripts in terms of metacognition patterns, and what we interpreted from students' self-reporting of their experience as a facilitator and participant in the student-led discussion activity. In determining the effectiveness of student-led discussions, we sought to capture how students described their experiences and how those experiences reflected metacognition processes.

\begin{tabular}{|c|c|c|}
\hline \multicolumn{3}{|c|}{ Metacognition in a Community of Inquiry } \\
\hline $\begin{array}{l}\text { Knowledge of Cognition } \\
\text { (KC) } \\
\text { (Entering } \\
\text { Knowledge/Motivation) }\end{array}$ & $\begin{array}{l}\text { Monitoring of Cognition } \\
\text { (MC) } \\
\text { (Assessment/Task Knowledge) }\end{array}$ & $\begin{array}{l}\text { Regulation of Cognition } \\
\text { (RC) } \\
\text { (Planning/Strategies) }\end{array}$ \\
\hline $\begin{array}{l}\text { Pre-Task Reflection } \\
\text { Knowledge of the inquiry } \\
\text { process } \\
\text { Knowledge of critical } \\
\text { thinking and problem } \\
\text { solving } \\
\text { Knowledge of factors that } \\
\text { influence inquiry and } \\
\text { thinking } \\
\text { Knowledge of self as a } \\
\text { learner } \\
\text { Entering motivational } \\
\text { state } \\
\text { Knowledge of discipline } \\
\text { Knowledge of previous } \\
\text { experiences } \\
\text { Expectancy of success }\end{array}$ & $\begin{array}{l}\text { Reflection on Action } \\
\text { Declarative; judging } \\
\text { Commenting on task, problem } \\
\text { or discussion thread } \\
\text { Asking questions for } \\
\text { confirmation of understanding } \\
\text { Commenting about self's and } \\
\text { others' understanding } \\
\text { Making judgments about } \\
\text { validity of content } \\
\text { Commenting on or making } \\
\text { judgments about the strategy } \\
\text { applied questions about } \\
\text { Asking or stalling } \\
\text { progression or } \\
\text { Expressing emotions during } \\
\text { learning } \\
\text { Assessing motivational state and } \\
\text { effort required }\end{array}$ & $\begin{array}{l}\text { Reflection in Action } \\
\text { Procedural; planning } \\
\text { Setting goals } \\
\text { Applying strategies } \\
\text { Providing/asking for support } \\
\text { Challenging self or others } \\
\text { Asking questions to deepen thinking } \\
\text { Asking for clarification } \\
\text { Request information } \\
\text { Self questioning } \\
\text { Questioning progression, success } \\
\text { Taking control of motivation and } \\
\text { effort } \\
\text { Facilitating/directing inquiry }\end{array}$ \\
\hline
\end{tabular}

Figure 1. The metacognition construct. From “Assessing Metacognition in an Online Community of Inquiry” by Akyol, Z. and Garrison, R.D. (2011). The Internet and Higher Education, 14, (p. 185). Copyright [2011] by Elsevier Inc. Reprinted with permission. 


\section{A. Justification: Gaps in the Literature on Metacognition in Online Discussions}

Since the study of metacognition in online learning is a recent trend, we identified three research gaps that inspired and extended our study of Akyol and Garrison's (2011) theory. The first gap involved a lack of understanding of how metacognition is manifested in online discussions, given that asynchronous online discussions are used predominantly for supporting teaching, learning, and collaborative activities in online learning. The purpose of Akyol and Garrison's study was to develop and validate a metacognition construct to assess three dimensions of metacognition (see Fig. 1) based on indicators adapted from the CoI framework. The validation of their metacognition construct was limited by assessing one online graduate course, suggesting that more studies and data are needed. We sought to extend this effort in validating the metacognition construct.

A second gap was in the identification of effective instructional strategies that facilitate metacognition in online discussions. Akyol and Garrison (2011) identified the need to develop new strategies for supporting the metacognition process in an online community of inquiry (CoI). In particular, we were interested in whether student-led facilitation (2009) was an effective instructional strategy for supporting the development of metacognition in online contexts.

A third gap was the limited methodological choices that have been applied in the research to examine metacognition in online discussions. Akyol and Garrison (2011) applied content analysis to quantitative data derived from archived discussion transcripts, but they recommended a qualitative approach (i.e., interviewing) could "further verify the indicators of each dimension of metacognition" (p. 189). We interpreted this gap to mean that content analysis of discussion postings was limited in the scope of exploring meaning and identifying the essences of online discussions. Hull and Saxon (2009) also suggested a need to move beyond the counting of posts to a more qualitative approach - that is, exploring the nature of the interactions within an asynchronous discussion forum.

We sought to extend our understanding of Akyol and Garrison's (2011) work by using these gaps as a strategic approach to frame new discovery about how metacognition is manifested in online discussions. We approached Akyol and Garrison's work as a starting point for pragmatic orientation. But we also sought to learn what was known and not known about metacognition in online discussions by not narrowing or limiting our scope strictly to an a priori approach (Chenail, Cooper, \& Desir, 2010). Therefore, we considered novel methods for qualitative research analysis to explore the qualitative nature of metacognition in online discussions.

\section{PURPOSE AND RESEARCH QUESTIONS}

We approached metacognition as the phenomenon of interest with a methodological objective of evaluating the relevance of Akyol and Garrison's (2011) construct. We also had a content objective to study student-led facilitation of discussions as a strategy in promoting metacognition. Therefore, the purpose was to explore: (1) where metacognition is evident in student-led online discussions and (2) how students' experiences leading and participating in student-led online discussions relate to their awareness of learning. Four research questions guided our inquiry:

What indicators of metacognition in a community of inquiry (CoI) are evident in student-led online discussions?

What are students' perceptions about leading and participating in student-led online discussions?

How do students' perceptions of their student-led discussion experiences reflect metacognition processes?

What are the implications on the design of online student-led activities? 


\section{RESEARCH DESIGN}

We took a qualitative approach to analyzing the data and employed two qualitative analysis methods: content analysis (Sandelowski, 2000; Smith, 2000) to analyze discussion forum transcripts, and interpretative phenomenological analysis (IPA) (Smith, Flowers, \& Larkin, 2009) to analyze student-led discussion questionnaire responses.

\section{A. Site and Participants}

The study took place in the context of an online master's course titled "Communities of Practice (CoP)" in a learning technology graduate program. The first author taught the course. The course was fully online and included four assignments: a reflection paper (20 points); mini research paper (30 points); online learning CoP plan and prototype (30 points); as well as student discussion forum participation and facilitation (i.e., student-led discussions) (20 points).

In the course syllabus, guidelines were given about the student-led discussions including expectations, directions, and format. A list of bi-weekly topics and readings was given to students at the beginning of the semester. During the first week of class, students emailed the professor indicating their first, second, and third choices of bi-weekly segments to facilitate. The professor organized the schedule based on choices and distributed the updated schedule via Blackboard's Course Announcements. The professor modeled the facilitation process during the second and third weeks of the term. Specifically, studentfacilitators were instructed to: read the assigned readings in advance of their facilitation dates, introduce the discussion topic/readings, provide guiding questions for the discussion, encourage participation, keep the discussion focused, encourage multiple viewpoints of the same issue(s), and bring the discussion to an end by summarizing highlights ( 1 or 2 short paragraphs).

Twelve students participated in the online discussions and six students completed a questionnaire at the end of the term regarding their experiences in the student-led discussions. After receiving approval from the university’s Institutional Review Board (IRB), data collection and analysis commenced.

\section{B. Data Sources}

The two primary data sources were the archived transcripts from discussion postings, and the anonymous student text responses to a Web-based questionnaire given at the end of the term. Similar to Akyol and Garrison's (2011) method of selecting transcripts from the first, fifth, and ninth weeks of a nine-week course for analysis, we selected three distinct two-week-long student-led discussion segments from the 14-week semester. Cases (A, B, and C) were selected from the beginning, middle, and end of the studentled discussions. In doing so, we used Miles and Huberman's (as cited in Marshall \& Rossman, 2011) definition of a typical case as these cases highlighted discussions that were "normal or average" (p. 111).

The student-led discussion questionnaire consisted of eight questions regarding students' opinions about the student-led discussion activity. The questions were open-ended and designed to gain feedback about 1) how the activity facilitated metacognition (e.g., how the activity helped them learn the course content), 2) how the activity was designed (e.g., bi-weekly discussion timeline, one or more facilitators running different discussions during the same time period), and 3) students' overall perceptions about the value of the student-led discussions.

\section{Data Analysis}

In exploring the first research question, "What indicators of metacognition in a community of inquiry (CoI) are evident in student-led online discussions?" we analyzed discussion transcripts in two ways. First, we used a priori codes derived from Akyol and Garrison's (2011) metacognition construct and Garrison and Akyol's (2013) metacognition questionnaire. Then, we used an inductive approach (Sandelowski, 2000) to develop codes "generated from the data" (p. 338). It is important to distinguish between content analysis in quantitative studies and qualitative studies. Sandelowski (2000) explained that both types of studies involve counting responses, however "in qualitative content analysis, counting 
is a means to an end, not the end itself" (p. 338). She further distinguished "the end result of counting is not a quasi-statistical rendering of the data, but rather a description of the patterns or regularities in that data that have, in part, been discovered and then confirmed by counting” (p. 338).

While we sought to evaluate the relevance of Akyol and Garrison's (2011) construct, our perspective of the phenomenon of interest was drawn from the descriptive indicators that were provided for each of the three dimensions. However, we were aware that the application of the metacognition construct in assessing metacognition in online discussions has not been validated fully. In addition, the metacognitive descriptors were open to interpretation, meaning they were not defined concretely. This is an important position statement on our part that we intended to review and identify what we saw in the data to determine if and how Akyol and Garrison's construct was relevant and evident in the context of asynchronous student-led discussions. Therefore, we remained open to the discovery of meaning of the data throughout the analysis.

We used interpretative phenomenological analysis (IPA) (Smith, et al., 2009) to analyze responses to the student-led discussion questionnaires. As an interpretative theory and method, Smith and Osborn (2003) indicated that IPA involves a two-stage interpretation process, or "a double hermeneutic," in that the participant is trying to make sense of their experience and the researcher is trying to make sense of the participant's experience (p. 53). The written responses of students' perceptions of their student-led discussion experiences were coded into categories of events and meaning of events (Smith, et al., 2009). By examining the content of online discussions and student responses to the questionnaire using these exploratory and descriptive methods, we were able to gain a better understanding how metacognition can be facilitated and manifested in online discussions.

\section{Analysis of Discussion Forum Transcripts Using A Priori Coding Approach}

Akyol and Garrison (2011) performed content analysis of forum transcripts by contextually coding the data (i.e., forum postings as the unit of analysis) in identifying instances of specific indicators from the three metacognitive dimensions presented in their construct. For example, indicators for monitoring of cognition (MC) include commenting on a task, asking questions for confirmation of understanding, and expressing emotions during learning (See Figure 1). They coded each posting by identifying the evidence of MC indicators as well as the other dimensions and related indicators from the construct.

We developed a coding guide (See Appendices) using Akyol and Garrison's (2011) construct and metacognition questionnaire (Garrison \& Akyol, 2013). This guide was used to help us identify instances of metacognition and organize the data. One discussion post was the unit of analysis. While in some cases, we coded several examples of one or more of the dimensions in one post, we did not count all instances. Instead, we followed the approach used by Akyol and Garrison and counted the number of messages in each case that showed at least one or more instances of each of the dimensions. The first author analyzed and coded the transcripts from weeks 4-5 (Case A), 8-9 (Case B) and 12-13 (Case C) and identified indicators in the text that reflected each of the three dimensions. The second author reviewed the coded transcripts so that we could discuss the usefulness of the metacognition construct in assessing metacognition in the transcripts and also to ensure that the codes represented each dimension (Smith, 2000).

\section{Analysis of Transcripts Using Inductive Coding Approach}

After we analyzed the cases using a priori codes, the first author analyzed the transcripts again without the codes. The purpose for conducting this second analysis was to gain new insights about the data that might shed light on how metacognition is manifested in the student-led discussions. To begin this process, the first researcher read through the transcripts making notes and memos reflected her thinking. Next, she read and re-read the transcripts and developed a set of open codes. These open codes were then categorized into themes. 


\section{Analysis of Student-Led Discussion Questionnaire}

We applied interpretative phenomenological analysis (IPA) (Smith, et al., 2009) to our investigation of the student-led discussion questionnaire responses. The questionnaire consisted of eight open-ended questions about students' opinions of the student-led discussion activity (see Appendices). This analysis addresses research question two: "What are students' perceptions about leading and participating in student-led online discussions?" question three: "How do students' perceptions of their student-led discussion experiences reflect metacognition processes?" and question four: "What are the implications on the design of online student-led activities?” Smith et al. (2009) suggested using the following six-step process for analyzing interview data: 1) immerse oneself in the data; 2) take notes including descriptive, linguistic, and conceptual comments; 3) develop emergent themes; 4) search for connections across emergent themes; 5) move to next case; and 6) look for patterns across cases.

\section{RESULTS AND INTERPRETATIONS}

\section{A. Results: Analysis of Discussion Forum Transcripts Using A Priori Codes}

Three key findings resulted from this analysis. First, students' metacognitive behaviors were observable in online learning environments. This finding is consistent with Akyol and Garrison's (2011) and Garrison and Akyol's (2013) research. Second, instances of all three indicators (KC, MC, and RC) were observed. However, there was overlap and it was difficult during the coding process to separate statements into these three dimensions. Third, in looking across all three cases, we observed more instances of MC than KC and RC. Garrison and Akyol (2013) stated, "MC reflects the individual perspective of an educational community of inquiry" (p. 86). We found most statements to reflect MC indicators. Garrison and Akyol also stated, "regulation of cognition contextualizes the learning dynamic consistent with a purposeful learning community" (p. 86). We coded the least amount of statements as those reflecting the RC dimensions. Table 1 shows the percentages of dimensions of metacognition in student-led online discussions.

Table 1

Percentages of Dimensions of Metacognition in Student-led Online Discussions

\begin{tabular}{|l|l|l|l|l|}
\hline Case & \# of Messages & Knowledge & Monitoring & Regulation \\
\hline $\begin{array}{l}\text { CASE A (Weeks } \\
\text { 4\&5) }\end{array}$ & 13 & (3) $23.0 \%$ & $(12) 92.3 \%$ & (5) $38.4 \%$ \\
\hline $\begin{array}{l}\text { CASE B (Weeks } \\
8 \& 9)\end{array}$ & 20 & (7) $35.0 \%$ & $(18) 90.0 \%$ & (6) $35.0 \%$ \\
\hline $\begin{array}{l}\text { CASE C (Weeks } \\
\text { 13\&14) }\end{array}$ & 25 & (7) $(28.0 \%$ & (20) $80.0 \%$ & (9) $36.0 \%$ \\
\hline
\end{tabular}


Table 2 shows examples of quotes from the transcripts and how they were coded using Akyol and Garrison's (2011) metacognition construct and Garrison and Akyol's (2013) metacognition questionnaire items.

Table 2

Coding Examples from Case B Using A Priori Codes

\begin{tabular}{|l|l|}
\hline $\begin{array}{l}\text { Metacognition } \\
\text { Dimension }\end{array}$ & $\begin{array}{l}\text { Quotes and References to Akyol and Garrison's } \\
\text { Metacognition Construct (2011) and Garrison and Akyol's (2013) } \\
\text { Metacognition Questionnaire }\end{array}$ \\
\hline $\begin{array}{l}\text { Knowledge of } \\
\text { (KC) }\end{array}$ & $\begin{array}{l}\text { "Not only am I more interested in reading the posts of my classmates, } \\
\text { I also feel a sense of community with them." } \\
\text { Construct: Entering motivational state } \\
\text { Questionnaire: "I know my motivational state at the beginning of the } \\
\text { learning process." }\end{array}$ \\
\hline $\begin{array}{l}\text { Monitoring of } \\
\text { (MC) }\end{array}$ & $\begin{array}{l}\text { "I am much more engaged in a class where I feel some connection } \\
\text { with the instructor, or that the instructor cares if I understand." } \\
\text { Construct: Assessing motivational state and effort required } \\
\text { Questionnaire: "I realize I need confirmation of my understanding." }\end{array}$ \\
\hline $\begin{array}{l}\text { Regulation of } \\
\text { (RC) }\end{array}$ & $\begin{array}{l}\text { "What activities did the instructor present that made students want to } \\
\text { engage with one another and experience reflective thought beyond a } \\
\text { simple question in a discussion post?" } \\
\text { Construct: Asking questions to deepen thinking } \\
\text { Questionnaire: "I ask questions to deepen thinking." }\end{array}$ \\
\hline
\end{tabular}

\section{B. Results: Analysis of Discussion Transcripts Using Inductive Approach}

The inductive analysis approach resulted in 51 open codes which were categorized into the following six themes:

Acknowledges Others (e.g., greets students, refers to another student's post, agrees/disagrees)

Engages Others (e.g., encourages participation, asks specific questions directed toward classmates, asks follow-up questions)

Self-Discloses (e.g., expresses emotion, shares personal beliefs, shares personal experiences)

Self-Reflects (e.g., self-questions and "I've thought about this...)

Declares Knowledge (e.g., extends discussion, states opinion, makes an inference, references literature, synthesizes information, summarizes discussion)

Interacts (e.g., student-to-student(s)/class, student-to-facilitator, facilitator-to-student(s)/class)

Figure 2 is a visual representation of the inductive analysis of the discussion forum transcripts. The five themes: acknowledges others, engages others, self-discloses, self-reflects, and declares knowledge represent how students made sense of the discussion topics both individually and collaboratively. The sixth theme, interacts, is represented as the roots given these interactions supported the growth and development of the discussion. Students not only constructed knowledge internally through self-reflection and declarative knowledge but also helped to facilitate learning through their interactions with others by acknowledging classmates' contributions, engaging them in dialogue, and self-disclosing. The doubleheaded arrow in between self-regulation (constructing meaning) and co-regulation (facilitating learning) represents the back and forth between internal knowledge construction and co-construction of meaning as described by Garrison and Akyol (2013). 


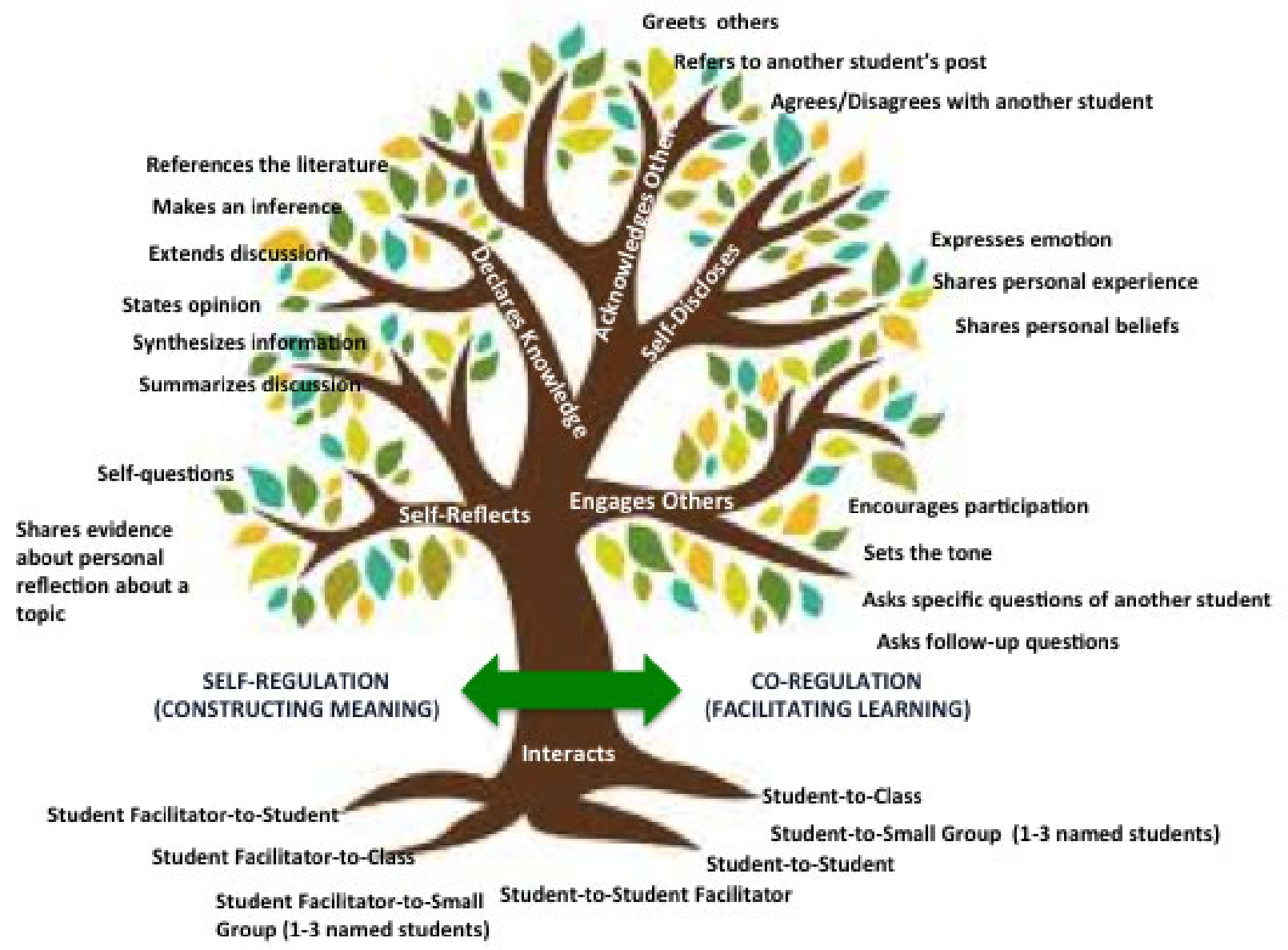

Figure 2. Visual Representation of Inductive Coding of Transcripts from a Student-led Online Discussion

\section{Results and Interpretations of the Analysis of Student-Led Discussion Questionnaire}

How students perceive their participation in student-led discussions and how their perceptions reflect metacognitive processes were categorized into the following nine themes:

Preparation

Perceived role as facilitator

Perceived responsibilities as facilitator

Effects of facilitator role

Perceived role as participant

Perceived helpfulness of student-led discussions

Difficulties in shifting roles

General perceptions about student-led discussion activity

Logistics - student-led discussion activity design

Each of the nine themes is presented here along with their associated events and meanings. In this section the "I" and the "P" in interpretative phenomenological analysis (IPA) are emphasized. Smith, et al. (2009) reminded researchers, "At each stage the analysis does indeed take you further away from the participant and includes more of you. However, the 'you' is closely involved with the lived experiences of the participant—and the resulting analysis will be a product of both of your collaborative efforts” (p. 92). We 
approached this inquiry as seasoned online instructors who have expertise in instructional design and online learning environments. We attribute the design of this course and inclusion of SLDs to our socialconstructivist philosophy. Although we attempted to bracket our preconceptions and stay open to the data, one is never free of all bias. As such, we acted as researchers and participants and engaged in a double hermeneutic loop in which we attempted to make sense of the learner's, who were making sense of their facilitation experiences (Smith et al., 2009).

\section{Theme One: Preparation}

\section{a. Events}

When describing their experience of preparing to lead their two-week segment of the online discussion, students noted the following:

"I prepared by reading the chapters."

"I read the content a few times and did some brainstorming on discussion topics/key points."

"I read the chapter and thought about the nine orientations of a CoP identified by the authors. Since [our class] uses on Blackboard as our orientation, I thought it would be interesting to see what other orientations the class thought would facilitate our learning together."

The amount of time students reported needing to prepare to lead a discussion varied from two hours to one week, with an average time of about three hours.

\section{b. Meanings}

Based on these findings, it seems learners take their role as facilitator seriously and want to appear prepared and knowledgeable about the topic when leading a discussion with their peers. How can this preparation activity be designed to leverage metacognitive skills? That is, are preparation activities such as the ones reported by students (i.e., reading, re-reading, brainstorming, and thinking about the readings within a specific framework) the most effective preparation strategies? Perhaps if we could teach preparation strategies that are research-based as opposed to relying on the learner's use of "improvised strategies” (McCabe, 2011, p. 463) we could promote explicit metacognitive awareness (Schraw, 1998) early on in the facilitation process.

\section{Theme Two: Perceived role as facilitator}

\section{a. Events}

Students identified various roles they played as facilitator including:

Discussion forum guide - "I read the chapter giving thought to how I would facilitate a discussion on the topics covered."

Content expert - "I felt that I had to study the course content more closely." "I felt as if I had to know that material more authoritatively than my peers who would be answering my questions so that I could properly respond.”

Content guide - "I had to choose one or two things to focus the discussion on so I wanted to make sure I understood each aspect first.”

Discussion prompter - "I would try to come up with more engaging questions."

Crafter of "good questions" - "I would attempt to craft questions which were closed-ended enough to get my peers to think about the chapter but open-ended enough that they could take ownership of their response.”

Motivator - "I would try to motivate others with more thoughtful responses."

\section{b. Meanings}

Students readily accepted the role of facilitator. In that role, none of the students described his/her role as the authority figure. While one student indicated he/she felt the need to understand the material "more 
authoritatively than my peers," there was not an indication that students felt the need to be experts. This self-perceived role of serving as a guide rather than an authority figure is consistent with constructivist pedagogy (Harasim, 2012). Students perceive their role in the learning process not as a passive student but one who is willing and capable of guiding others.

\section{Theme Three: Perceived responsibilities as a facilitator}

\section{a. Events}

With regard to students' perceptions about leading and participating in student-led online discussions, the majority of comments pertained to their role as facilitator. Activities students engaged in as a facilitator included:

Preparing - "I spent the week prior readying for my discussion questions.”

Reading - "I read through the materials and tried to identify the crux of the chapter."

Brainstorming - "I read the content a few times and did some brainstorming on discussion topics/key points.”

Crafting questions - "I would attempt to craft questions which were closed-ended enough to get my peers to think about the chapter but open-ended enough that they could take ownership of their response."

Monitoring - "I also would have tried to log in every day to at least check in on how the topic was progressing. If I missed a day I felt like I was behind and had to catch up on what was happening."

Motivating others - "I would try to motivate others with more thoughtful responses."

\section{b. Meanings}

These findings indicate student facilitators were aware of a responsibility to the group to lead and facilitate discussion in a way that fosters deep learning. These activities reflect metacognitive dimensions identified by Akyol and Garrison (2011). For example, the first three bullet points reflect indicators of KC including knowledge of the inquiry process, knowledge of self as learner, and entering motivational state. These activities seem to be focused on helping the student-facilitator acquire and comprehend information in order to facilitate the discussion effectively. The last three bullet points reflect indicators of RC including applying strategies, procedural/planning, and taking control of motivation and effort. These types of regulatory skills, however, seem to be focused outward toward the student-facilitator's classmates. That is, it appears these regulatory skills were applied to help facilitate the learning of the group, rather than the learning of the individual.

\section{Theme Four: Effects of facilitator role}

\section{a. Events}

Based on students' descriptions of their experience as a student facilitator, it appears they applied many of the regulation of cognition (RC) planning techniques and strategies outlined by Akyol and Garrison (2011). For example, some of the comments that reflect "procedural/planning” (Akyol \& Garrison, 2011, p. 185) include:

"I read the chapter giving thought to how I would facilitate a discussion on the topics covered."

"I had to choose one or two things to focus the discussion so I wanted to make sure I understood each aspect first."

"I felt that I had to study the course content more closely."

Comments that reflect application of strategies such as "providing/asking for support; challenging self or others; asking questions to deepen thinking; asking for clarification; request information; selfquestioning)” (Akyol \& Garrison, 2011, p. 185) include:

"I would attempt to craft questions which were closed-ended enough to get my peers to think about the chapter but open-ended enough that they could take ownership of their response.” (Strategy: Asking questions to deepen thinking) 
"Being the facilitator made me look at the content from a different perspective." (Strategy: Selfquestioning)

A comment that reflects “questioning progression/success” (Akyol \& Garrison, 2011, p. 185) is:

“...but facilitating helped me by making me look for deeper meaning among the participants' comments and continue [to] review the reading assignment a few times with a more critical eye.”

Comments that reflect "taking control of motivation and effort" and/or "facilitating/directing inquiry" (Akyol \& Garrison, p. 185) are:

"I felt as if I had to know the material more authoritatively than my peers who would be answering my questions so that I could properly respond.”

"I would try to come up with more engaging questions..."

"I would try to motivate others with more thoughtful responses."

\section{b. Meanings}

These comments reflect the indicators that Akyol and Garrison (2011) identify under regulation of cognition (RC) almost exclusively. The student facilitator is not only making sense of the task individually but is also aiming to deepen one's understanding through the process of facilitating discussion among his/her peers. Taking on the role of student-facilitator required the student to apply these strategies more so than as a participant, simply because of the nature of the task. With regard to this type of shared agency - when all students share the role of learner and facilitator, Martin (2013) stated, "When this capacity shifts from one central figure to multiple participants, all community members acquire both a right and a duty to influence the community" (p. 150). Thus, through this responsibility to the class, the student-facilitator is applying strategies that could also help him/her develop metacognitive skills.

\section{Theme Five: Perceived role as participant}

\section{a. Events}

When asked to reflect on their role as a participant in student-led discussions, students identified themselves as active participants and co-constructors of knowledge. For example, one student commented:

"I was a fellow-traveler who was being asked to co-construct/formulate an understanding of the materials being presented. I didn't have to be $100 \%$ and it was ok to ask questions and make suppositions in the dialogue which took place.”

Another student noted,

"The expectations of my role were to be an active participant."

\section{b. Meanings}

The student as a participant in the online discussions is a collaborator-one who is co-constructing meaning along with the student facilitator and the rest of the class. One might question whether the element of student-facilitation had any impact on the perceived role as participant. That is, because the student was leading the discussion instead of the instructor, were students more comfortable asking questions and making mistakes? Also, for those who took the role of student-facilitator early on, how did the role of student-facilitator impact their behavior as a participant later on in the semester? Did this experience help the student become more metacognitively aware?

\section{Theme Six: Perceived helpfulness of student-led discussions}

\section{a. Events}

While it seemed that the perceived role of student as facilitator reflected indicators of regulation of cognition (RC), when students were asked what they found most beneficial about the student-led discussions, responses seem to fall into the category of monitoring of cognition (MC). Table 4 shows 
students' comments about perceived helpfulness of student-led discussions with corresponding indicators from Garrison and Akyol's (2013) metacognition questionnaire.

Akyol and Garrison (2011) stated, “...the monitoring of cognition (MC) dimension specifically includes the awareness and willingness to reflect upon the learning process” (p. 184). Table 4 includes student comments that reflect monitoring of cognition (MC) indicators.

Table 4

Students' Comments about Perceived Helpfulness of Student-Led Discussions and Corresponding Indicators from Garrison and Akyol's (2013) Metacognition Questionnaire

\begin{tabular}{|l|l|}
\hline $\begin{array}{l}\text { Students' Comments about Perceived } \\
\text { Helpfulness of Student-Led Discussions }\end{array}$ & $\begin{array}{l}\text { Corresponding Indicators from Garrison and } \\
\text { Akyol's (2013, p. 86) Metacognition Questionnaire }\end{array}$ \\
\hline $\begin{array}{l}\text { "[The discussions] helped me understand } \\
\text { the readings and get different perspectives } \\
\text { from other students." }\end{array}$ & $\begin{array}{l}\text { MC - I realize I need confirmation of my } \\
\text { understanding. }\end{array}$ \\
\hline $\begin{array}{l}\text { "[The discussions] helped me gain a } \\
\text { deeper understanding of the content we } \\
\text { were reading." }\end{array}$ & $\begin{array}{l}\text { MC - I consciously assess my understanding during } \\
\text { the learning process. }\end{array}$ \\
$\begin{array}{l}\text { "I do think that the discussions helped me } \\
\text { understand some content that may have } \\
\text { been confusing. By reading others" } \\
\text { responses, it was easy to see another point } \\
\text { of view." }\end{array}$ & $\begin{array}{l}\text { MC - I pay attention to other course participants' } \\
\text { ideas / understandings /comments. }\end{array}$ \\
\hline $\begin{array}{l}\text { "I thought [student-led discussions] were } \\
\text { especially useful because it gave us an } \\
\text { opportunity to be a steward/facilitator of } \\
\text { our own mini-CoP - we had the } \\
\text { opportunity to see how the shoe fit.” }\end{array}$ & MC - I think about how we are approaching a task. \\
\hline
\end{tabular}

\section{b. Meanings}

Perhaps these comments reflect MC more than RC because students are reflecting upon how their involvement in facilitating the discussions helped them personally, thus internalizing the learning gained from the shared online discussions. Akyol and Garrison (2009) described how "Taking responsibility for teaching presence enables students to reflect on each other's contributions and their contribution to the developmental progress toward the intended goals while engaged in discourse" (p. 184). However, it is uncertain whether and how student-led discussions improve knowledge construction. For example, De Wever, Van Winckel, and Valcke (2008) found no significant difference in the level of knowledge construction between student-facilitated and instructor-facilitated discussions. However, they found significant differences between these two types of discussions when a student-facilitated discussion included another student role called, “developer of alternatives.” That is, when these two student roles were assigned within a discussion (i.e., facilitator and developer) higher levels of knowledge construction were achieved. These results have implications on the effective design of student-led discussion suggesting that additional student roles may need to be assigned.

\section{Theme Seven: Difficulties in shifting roles}

\section{a. Events}

Students were asked what they found to be the most difficult aspect of the student-led discussion assignment. The emergent theme from their responses was difficulties in shifting roles. This theme was drawn from statements like the following: 
"To me the most difficult part was knowing when to chime in as a facilitator. I know it is a fine line, I wanted to answer everyone but also didn’t want to dominate the discussion.”

Another student said,

"I also found that I didn't always know when to not comment during my facilitation week. I didn't want to scare anyone off, but I didn’t want to bombard and/or prod everyone who spoke up.”

A couple of students expressed feelings of uncertainty and uneasiness about leading a discussion but found in doing so, they felt more confident. One student said,

"Commenting in a discussion thread, much less leading the discussion is not something I am supercomfortable with. However, I do think that it helped me to face the fact that I hesitate in posting."

Another student commented,

"Online facilitation is not something I had experienced before and I now have more confidence (and some knowledge of what worked and didn’t work) to facilitate if asked again outside of this class.”

\section{b. Meanings}

Students describe difficulties that instructors also voice. As online instructors, we struggle with the same concerns regarding effective facilitation (e.g., what types of questions to ask, how often to participate, how much to guide the discussion, how to give good feedback, how to best summarize the discussion, and how to guide critical inquiry). These are issues that should be addressed when preparing students to facilitate online discussions.

\section{Theme Eight: General perceptions about student-led discussion activity}

\section{a. Events}

When asked about students' overall perceptions of student-led discussions, students described the experience as helpful, useful, valuable, enjoyable, safe, and comfortable. One student noted that he/she preferred instructor-led discussions. Two comments that reflect the overall general perceptions include:

"I like how each opinion was valued. I felt like I could explain what I was thinking freely and get feedback."

"At times there was a lot to process, but overall I enjoyed the discussions."

\section{b. Meanings}

The comments reveal general acceptance of student-led discussions as an enjoyable activity; however, there remains uncertainty (as expressed by the one student) that student-led discussions are less valued than instructor-led discussions.

\section{Theme Nine: Logistics - student-led discussion activity design}

\section{a. Events}

The final question asked for additional comments about the student-led discussion activity. These comments provided helpful insight regarding the logistics and design of student-led discussions. For example, students were generally okay with the bi-weekly timeline; however some felt more time was needed to process information. For example, on student noted: "Conversations need time to develop. I wish there was more time to respond. I would have loved to have gone back after reading things and answered questions from previous weeks.”

Students also commented on the variety of the discussion topics and the ability to collaborate with other students who were leading their discussion during the same timeframe. One student noted his/her frustration with students waiting until the end of the time period to post a comment.

\section{b. Meanings}

Perhaps the student-led discussions could be set up in a way that provided a general timeline but also allowed enough flexibility for students to revisit discussion threads. Further, it seems it would be 
An Exploration of Metacognition in Asynchronous Student-Led Discussions

beneficial to allow time before the end of the semester where there is not guided discussion but rather an opportunity for students to reflect on and share their experiences. The issue of waiting until the end of the time period to post could be addressed by acknowledging students who maintain a steady presence in the discussion from beginning to end.

\section{DISCUSSION}

We found that Akyol and Garrison's (2009) metacognition construct was useful in exploring and examining deep instances of metacognition in online discussion forums. The results from the analysis of discussion forum transcripts using an inductive content analysis approach sheds more light on what happens in student-led discussions, and this information can aid researchers and practitioners to better understand and assess metacognition and how it is manifested in online discussions. With regard to our first research question: "What indicators of metacognition in a community of inquiry (CoI) are evident in student-led online discussions?” we found instances of all three indicators of metacognition, knowledge, monitoring, and regulation. However, most comments reflected instances of monitoring of cognition with the majority of those instances reflecting declarative/judging statements. While metacognition can be coregulated, there was little evidence that students used the full range of metacognitive skills to help coconstruct meaning. However, these interpretations should be taken with caution given the inherent difficulty in observing metacognition. Regarding metacognitive activities, De Wever et al. (2008) warned, "Concluding that students do not perform any kind of metacognitive activity might be wrong, as the absence of metacognitive statements might be caused by the fact that students do not communicate explicitly about these activities" (p. 38).

Concerning research questions two: "What are students' perceptions about leading and participating in student-led online discussions?” and three: "How do students' perceptions of their student-led discussion experiences reflect metacognition processes?” we learned that students take the role of facilitator seriously and use metacognitive processes to help them prepare and act in that role. However, students expressed a feeling of tentativeness in their facilitator role and may lack the necessary skills to be effective. In a CoI, there is an expectation that aspects of teaching presence, such as facilitation of discourse, are shared among instructors and students. At the same time, it is taken for granted that students have the knowledge and skills to be successful in this role. Most students have limited knowledge and experience on how to be an effective online facilitator. While students may have some expertise facilitating a face-to-face discussion, they may be less likely to be able to facilitate a purely textbased discussion. These results imply the need to inform, educate, and motivate students in their roles as facilitators and teach them online facilitation strategies including how to use metacognitive strategies effectively. For example, informational resources and instructional modules on facilitation, as well as, metacognitive skills (i.e., assessing metacognitive awareness, questioning skills, feedback skills, making summaries, guiding critical inquiry) could be built into the design of the course or added as stand-alone instructional modules. When students demonstrate these skills within the course, instructors can privately or publicly (depending on the situation) acknowledge these students.

As for our fourth research question: "What are the implications on the design of online student-led activities?” we learned that student-led online discussions can be used as an effective instructional activity to promote metacognition. However, instruction and guidance are needed not only to help students become aware of metacognitive skills but also to learn how to use them effectively in an online discussion. In addition, assignment of student roles such as a developer of alternatives in addition to student as facilitator and student as participant in the online discussion may support the development of knowledge construction (DeWever, et al., 2008).

We acknowledge that this study has limitations. As a qualitative inquiry, we realize while our methods helped us examine metacognition in student-led online discussions in detail, results are limited to our personal interpretations of the data. However, we have attempted to provide transparency of our research process by providing clear and explicit details of our methods. A mixed methods study could help to offset the limitations of a purely qualitative study and present a more balanced portrayal of this 
phenomenon (Creswell, 2014). Also, the data represent one class of master's students within a specific course in a learning technology program. Future research in other knowledge domains could extend the generalization of these findings.

\section{CONCLUSIONS}

Akyol and Garrison (2011) suggested teachers and learners share roles and responsibilities in a CoI, and that these shared roles and responsibilities are inherent in the philosophical underpinnings of the CoI as a social-constructivist framework. However, Shea et al. (2012) noted while it is generally understood the teacher and the student to share roles within the context of teaching presence in a CoI, there are different motivations for teachers and students due to the nature of the outcomes of the educational experience. For example, students may engage in a CoI to acquire new knowledge and earn grades and/or credit, while teachers may engage in a CoI primarily to share knowledge and guide student learning experiences through effective instructional design and facilitation. These "real world dynamics that shape and constrain much of learning in practice” (p. 93) are important to recognize in order to extrapolate and address specific aspects about teaching presence within the context of those who participate in the CoI. One of these aspects is the facilitation of online discussions and how members (e.g., learners and teachers) in a CoI can use online discussions to achieve deeper learning. Metacognition (i.e., when one thinks about his/her learning) is a precursor to critical thinking and deep learning. Researchers have already acknowledged that metacognitive skills can be taught (Choi et al., 2005; Schraw, 1998) and that some metacognitive activities are more effective than others (Haller, Child, \& Walberg, 1998; McCabe, 2011). However, additional studies are needed that investigate the use of instructional strategies which facilitate the development of metacognitive awareness and skills (See Choi et al., 2005 for an example) and the ways teachers and learners can apply metacognitive skills effectively. If we can assess metacognition in online learning environments, in which learners are largely self-regulated, we can integrate design strategies and learning activities that support metacognition (e.g., sharing of cognitive experiences) in asynchronous discussion forums.

Taking an exploratory approach to data analysis helped us identify certain challenges in understanding how metacognition is manifested and facilitated in online discussions and why this understanding is important to know and to articulate to online learning practitioners. Future research could include the use of data visualization strategies to more effectively analyze the data and track patterns of metacognition dimensions as well as design-based studies that integrate information about metacognition and instructional strategies for developing metacognitive awareness and skills in an online learning environment. 


\section{REFERENCES}

Akyol, Z., \& Garrison, D.R. (2011). Assessing metacognition in an online community of inquiry. The Internet and Higher Education, 14, 183-190.

Baran, E., \& Correia, A. P. (2009). Student-led facilitation strategies in online discussions. Distance Education, 30(3), 339-361.

Chenail, R. J., Cooper, R., \& Desir, C. (2010). Strategically reviewing the research literature in qualitative research. Journal of Ethnographic \& Qualitative Research, 4, 88-94.

Choi, I., Land, S., Turgeon, A.J. (2005). Scaffolding peer questioning strategies to facilitate metacognition during online small group discussion. Instructional Science, 33, 483-511.

De Wever, B., Van Winckel, M., \& Valcke, M. (2008). Discussing patient management online: The impact of roles on knowledge construction for students interning at the paediatric ward. Advances in Health Sciences Education, 13(1), 25-42.

Flavell, J. H. (1979). Metacognition and cognitive monitoring: A new area of cognitive-developmental inquiry. American Psychologist, 34(10), 906-911.

Garner, R. (1990). When children and adults do not use learning strategies: Toward a theory of settings. Review of Educational Research, 60(4), 517-529.

Garrison, D.R. \& Akyol, Z. (2013). Toward the development of a metacognition construct for communities of inquiry. The Internet and Higher Education, 17, 84-89.

Garrison, D.R., Anderson, T. \& Archer, T. (2000). Critical inquiry in a text-based environment: Computer conferencing in higher education. The Internet and Higher Education 2(2-3), 87-105.

Garrison, D. R., \& Arbaugh, J. B. (2007). Researching the community of inquiry framework: Review, issues, and future directions. The Internet and Higher Education, 10, 157-172.

Harasim, L. (2012). Learning theory and online technologies. New York, NY: Taylor \& Francis Group.

Hart, J.T. (1965). Memory and the feeling-of-knowing experience. Journal of Educational Psychology, 56(4), 208-216.

Hull, D. M., \& Saxon, T. F. (2009). Negotiation of meaning and co-construction of knowledge: An experimental analysis of asynchronous online instruction. Computers \& Education, 52, 624-639.

Marshall, C. \& Rossman, G.B. (2011). Designing qualitative research (5 ${ }^{\text {th }}$ ed.). Thousand Oaks, CA: Sage Publications, Inc.

Martin, K.H. (2013). Leveraging disinhibition to increase student authority in asynchronous online discussion. Journal of Asynchronous Learning Networks, 17(3), 149.164.

Mayer, R.E. (1998). Cognitive, metacognitive, and motivational aspects of problem solving. Instructional Science, 26(1/2), 49-63.

McCabe, J. (2011). Metacognitive awareness of learning strategies in undergraduates. Memory and Cognition, 39(3), 462-476.

McInerney, D. M. (2005). Educational psychology - theory, research and teaching: A 25-year retrospective. Educational Psychology, 25(6), 585-599.

Palincsar, A. S. (1998). Social constructivist perspectives on teaching and learning. Annual Review of Psychology, 49, 345-375.

Sandelowski, M. (2000). Whatever happened to qualitative description? Research in Nursing \& Health, 23, 334-340. 
Schraw, G. (1998). Promoting general metacognitive awareness. Instructional Science, 26, 113-125.

Smith, C.P. (2000). Chapter twelve: Content analysis and narrative analysis. In Reis, H.T. and Judd, C.M. (Eds.), Handbook of research methods in social and personality psychology (pp. 313-335). New York, NY: Cambridge University Press.

Smith, J. A., Flowers, P., \& Larkin, M. (2009). Interpretative phenomenological analysis: Theory Method and research. London: Sage.

Smith, J. A., \& Osborn, M. (2003). Interpretative phenomenological analysis. In J.A. Smith (Ed.), Qualitative psychology: A practical guide to methods. London: Sage.

Young, A., \& Fry, J. D. (2008). Metacognitive awareness and academic achievement in college students. Journal of the Scholarship of Teaching and Learning, 8(2), 1-10.

\section{APPENDICES}

\section{A. Appendix A: Student-Led Discussion Questionnaire}

Thank you for participating in the student-led discussions for this course. I am interested in your opinions about this activity. Please take a few minutes to answer the following eight questions. Although completion of the questionnaire is purely optional, I value your input and your responses will remain completely anonymous.

As the facilitator of the discussion, how did you go about preparing for your particular discussion topic? What resources did you use? How much time did you spend preparing for your topic?

How did having to facilitate the discussion help you to learn the course content for your assigned period? Looking back, what would you do differently before, during, or after your assigned discussion? Why?

As a participant in the student-led discussion, what were your expectations of the role you played? Did the discussions help you communicate, explain, or justify your thinking? How?

Was the bi-weekly discussion timeline with two or more facilitators reasonable? Why? Why not?

Overall, what did you find most beneficial about the student-led discussion assignment?

Overall, what did you find most difficult about the student-led discussion assignment?

Please provide any additional comments related to the student-led discussion assignment that you wish to share.

\section{B. Appendix B: Coding Guide}

In addition to using the descriptors of knowledge of cognition, monitoring of cognition, and regulation of cognition from Akyol and Garrison's (2011) metacognition construct (See Figure 1), we used the following information to help us analyze the discussion forum transcripts.

\section{Knowledge of Cognition (KC) "Pre-Task Dimension"}

The "pre-task metacognitive state...Examples of KC are students' assessment of how they learn best, what they know or do not know about the subject matter, or how they feel with regard to the task or their ability” (Akyol \& Garrison, 2011, p. 184). "Taking on the responsibility of teaching presence, enables students to reflect on each other's contributions and their contribution to the developmental progress toward the intended goals while they are engaged in discourse” (Akyol \& Garrison, 2011, p. 184). Look for evidence in the discussion forum post that seem to show evidence of the following statements. (Statements from Garrison \& Akyol, 2013.)

I know my strengths as a learner.

I know my weaknesses as a learner.

I have good critical thinking skills 
I have good problem solving skills.

I know what factors may enhance my thinking and learning.

I know my motivational state at the beginning of the learning process.

I am clear on my opportunities for success.

I know my existing knowledge and experiences related to the learning task.

\section{Monitoring of Cognition (MC) - "Reflective Dimension"}

"The monitoring dimension specifically includes the awareness and willingness to reflect upon the learning process" (Akyol \& Garrison, 2011, p. 184). Look for evidence in the discussion forum post that seem to show evidence of the following statements. (Statements from Garrison \& Akyol, 2013.)

I make judgments about the difficulty of the tasks.

I am aware of my effort during the learning process.

I am aware of my level of thinking during the learning process.

I constantly monitor my feelings during the learning process.

I consciously assess my understanding during the learning process.

I realize I need confirmation of my understanding.

I pay attention to other course participants' ideas/understandings/comments.

I think about how we are approaching the task.

\section{Regulation of Cognition (RC) - “Active Dimension”}

Regulation of cognition is the "action dimension of the learning experience. It is the enactment and control of the learning process through the employment of strategies to achieve meaningful learning outcomes" (Akyol \& Garrison, 2011, p. 184). Look for evidence in the discussion forum post that seem to show evidence of the following statements. (Statements from Garrison \& Akyol, 2013.)

I set goals to achieve a high level of learning.

I modify my approach to enhance my effort.

I ask questions or request information to deepen my thinking.

I challenge myself and other course participants.

I make suggestions to other course participants to help their learning.

I apply specific strategies to enhance my understanding.

I ask for help when I encounter difficulty.

I modify my goals or strategies when I encounter difficulty in understanding.

I change my strategy depending on the tasks.

I try to control my anxiety to enhance my understanding. 